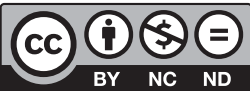

Estudos Teológicos foi licenciado com uma Licença Creative Commons Atribuição - NãoComercial - SemDerivados 3.0 Não Adaptada

http://dx.doi.org/10.22351/et.v60i3.3593

\title{
O Querigma do Cristo ressignificado: O MOTIVO DA EXPULSÃO DOS GRUPOS JOANINOS DA SINAGOGA ${ }^{1}$
}

The Kerygma of the ressignified Christ:

The reason for the expulsion of Johannine groups of synagogue

Danilo Dourado Guerra²

Resumo: O presente artigo busca assinalar que o marco histórico da expulsão dos grupos joaninos da sinagoga fixa-se como um paradigma efeitual oriundo do querigma messiânico joanino. Sob esse viés, nossa tese é que os grupos joaninos foram expulsos da sinagoga por proclamarem Jesus como um Messias davídico popular ressignificado. Nessa paisagem, o querigma do herói joanino como o Messias que não se origina neste mundo, advindo do fragmento de João 18.36 como memória, faz-se reflexo de um processo de ressignificação messianológica joanina e, por conseguinte, torna-se elemento catalisador dessa expulsão.

Palavras-chave: Cristologia joanina. Messianismo popular. Herói. Heterotopia.

Abstract: The present article seeks to point out that the historical landmark of the expulsion of the Johannine groups from the synagogue is fixed as an effective paradigm originating from the messianic kerygma Johannine. In this aspect, our thesis is that the Johannine groups were expelled from the synagogue for proclaiming Jesus as a ressignified popular Davidic Messiah. In this landscape, the kerygma of the Johannine hero as the Messiah who does not originate in this world, coming from the fragment John 18,36 as memory, is a reflection of a process of Johannine messianic re-signification and, therefore, becomes a catalyst element of this expulsion.

Keywords: Johannine Christology. Popular Messianism. Hero. Heterotopia.

1 O artigo foi recebido em 20 de fevereiro de 2019 e aprovado em 02 de agosto de 2019 com base nas avaliações dos pareceristas ad hoc.

2 Doutor. Faculdade Araguaia. E-mail: daniloatlanta@gmail.com 


\section{Introdução}

Há muito tempo o marco histórico-efeitual ${ }^{3}$ da expulsão dos grupos joaninos do espaço sinagogal, apesar da sua não consensualidade ${ }^{4}$, tem sido tema de debates dentro dos estudos do Quarto Evangelho. ${ }^{5}$ Nesse aspecto, a arena conflituosa estabelecida entre o judaísmo rabínico em (re)formulação e os grupos joaninos em um panorama sinagogal pós-70 d.C. não se faz novidade em se tratando dos estudos acerca do evangelho joanino. À luz desse contexto de efeitos e conflitos, a tese da expulsão da comunidade joanina da sinagoga tornou-se um metaponto histórico-exegético para os estudos joaninos. Sob esse prisma, diversas investigações e hipóteses foram construídas com a finalidade de evidenciar tanto a veracidade histórica quanto o(s) motivo(s) dessa expulsão. Essas pesquisas, em sua maioria, têm corretamente afirmado que o fenômeno da exclusão dos grupos joaninos ocorreu devido à proclamação da figura de Jesus como o Messias esperado dentro do judaísmo. Entretanto, a despeito das diversas investigações acerca do tema, poucos estudos têm avançado no sentido de propor

3 Cf. GADAMER, Hans-Georg. Verdade e Método I: traços fundamentais de uma hermenêutica filosófica. Trad. Flávio Paulo Meuer. Petrópolis: Vozes, 1997. Em sua assertiva construção teórica acerca do fenômeno hermenêutico que envolve a história das interpretações, Gadamer (1997) apresenta-nos o que denomina de história efeitual. De acordo com sua definição, "o interesse histórico não se orienta somente pelos fenômenos históricos ou pelas obras transmitidas, mas tem como temática secundária o efeito dos mesmos na história (o que implica também a história da investigação)" (GADAMER, 1997, p. 449). Em outros termos, "quando procuramos compreender um fenômeno histórico a partir da distância histórica que determina nossa situação hermenêutica como um todo, encontramo-nos sempre sob os efeitos dessa história efeitual" (GADAMER, 1997, p. 449). Esse conceito de história efeitual norteará a presente investigação.

4 Estamos cientes da existência de pesquisas que questionam a reconstrução histórica da expulsão sinagogal dos grupos joaninos, contudo, optamos pela vertente exegética que a visibiliza. Para um aprofundamento crítico em relação à expulsão sinagogal, cf. BERNIER, Jonathan. Aposynagogos and the Historical Jesus in John: Rethinking the Historicity of the Johannine Expulsion Passages. Leiden: Brill, 2014.

5 Entre os estudos acerca da expulsão sinagogal estão as obras de: LINDARS, B. John. In: The Johannine literature. Sheffield: Sheffield Academic, 2000. p. 30-109. MARTYN, J. Louis. History \& Theology in the Fourth Gospel. Nashville: Abingdon, 1979a. __. The gospel of John in Christian history: essays for interpreters. New York: Paulist, 1979b. STEGEMANN, Ekkehard W.; STEGEMANN, Wolfgang. História social do protocristianismo: os primórdios do judaísmo e as comunidades de Cristo no mundo mediterrâneo. Trad. Nélio Schneider. São Leopoldo: Sinodal, 2004. TEPEDINO, Ana Maria Azevedo Lopes. Espiritualidade e ética: Jesus Cristo e a História da Comunidade joanina. Tese (Doutorado em Teologia) - PUC/RJ, Rio de Janeiro, 1993. VIDAL, Senén. Evangelio y Cartas de Juan: Génesis de los textos juánicos. Bilbao: Mensajero, 2013. WENGST, Klaus. Interpretación del Evangelio de Juan. Salamanca: Sígueme, 1988. Em termos exegéticos, o pioneirismo da hipótese da expulsão sinagogal pode ser visto nas pesquisas de Louis Martyn (1979a; 1979b), sobretudo, em sua análise da narrativa de João 9. Martyn (1979a) começa com João 9 por duas razões. Essa narrativa repousa na tradição cristã. E que a mesma convida à distinção entre os elementos da tradição e os que provêm do próprio evangelista do Quarto Evangelho. Para MARTYN (1979a), essa primeira situação traumática para a comunidade joanina pode ser observada através do termo grego chave aposynagogos. De acordo com VIDAL (2013), a expulsão da sinagoga de que fala João 9.22 é evidentemente a exclusão definitiva da cena do judaísmo e não um simples castigo temporal, e não uma simples expulsão do ambiente de julgamento. Segundo ele, o tema da expulsão sinagogal também aparece em João 9.34; 12.42 e 16.2. 
uma digital messianológica ${ }^{6}$ específica como fator dessa expulsão. ${ }^{7}$ Em outros termos, postula-se que a expulsão teria sido ocasionada pelo querigma do Cristo joanino. Mas que Cristo seria esse? No conteúdo dessa resposta encontra-se o paradigma da expulsão. Esse espectro cristológico nos revela a face do herói ${ }^{8}$ joanino.

Kierkegaard (s.d.), ao tratar da figura do herói, remete ao personagem mítico que paradoxalmente desafia sua época e escandaliza o seu mundo. Tal arquétipo faz-se candente no panorama joanino, especialmente na atualização do fragmento de João 18.36 por meio da anamnese da comunidade. Nesse inédito e enigmático fragmento textual, a memória joanina transporta-nos para um palco homérico, onde o herói joanino diante de Pôncio Pilatos profere a escandalosa prédica:

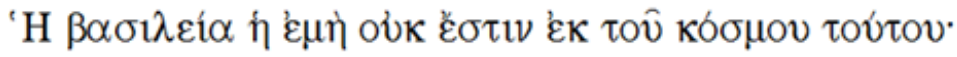

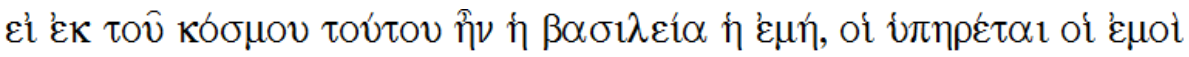

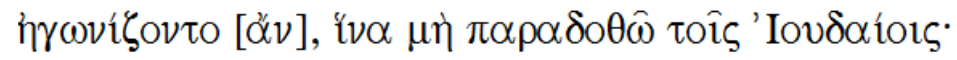

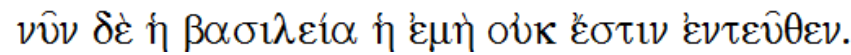

\author{
"Minha basileia não se origina neste mundo. \\ Se se originasse, os meus servos lutariam para impedir \\ que os judeus me prendessem. \\ Mas agora a minha basileia não é daqui” (Jo 18.36 tradução própria).
}

No âmbito da vida dos grupos joaninos ${ }^{9}$, concebemos que o discurso de Jesus perante Pilatos fora recordado e acionado pela memória joanina, em tons de ineditis-

6 Neste texto, o neologismo "messianológico" se estabelece na medida em que concebemos a existência de estruturas racionais e lógicas acerca dos parâmetros interpretativos dos messianismos em Israel, isto é, pressupomos a existência cognitiva de uma "messianologia", ou "messianologias" no sentido de uma ideia, lógica ou interpretação acerca do Messias, em suas diversas vertentes e variáveis históricas.

7 A hipótese trabalhada neste artigo é uma apresentação sintética do que foi desenvolvido em nossa tese doutoral. Para maiores detalhes, cf. Heróis em cena: a construção paradigmática contracultual da mesocristologia joanina. Tese (Doutorado em Ciências da Religião) - Pontifícia Universidade Católica de Goiás, Goiânia, 2018.

8 Cf. BRO LARSEN, Kasper. Narrative Docetism: Christology and storytelling in the Gospel of John. In: BAUCKHAM, Richard; MOSSER, Carl (Orgs.). The Gospel of John and Christian theology. Grand Rapids: Eerdmans, 2008. p. 346-355. Diante de todas as faces do herói da antiguidade, a partir de um prisma narratológico dos evangelhos, Jesus pode ser concebido como o herói dos apóstolos. Sob essa perspectiva, um herói é definido por seu extraordinário conhecimento e/ou habilidade em comparação com os outros atores do mundo da narrativa (BRO LARSEN, 2008, p. 347-352).

9 Antes de tudo, consideramos o Quarto Evangelho (QE) sob o prisma hermenêutico de um duplo horizonte (MARTYN, 1979a). Por isso: "Temos que manter sempre em mente que o texto apresenta seu testemunho em dois níveis. (1) é o testemunho de um evento original durante a vida terrena de Jesus [...] (2) o texto também é o testemunho da presença poderosa de Jesus em eventos reais experimentados pela igreja Joanina" (MARTYN, 1979a, p. 30. [Tradução própria].). Sob a perspectiva do duplo horizonte, diante de Pilatos os olhos de Jesus e da comunidade joanina se confundem. 
$\mathrm{mo}^{10}$, num momento da comunidade em que se estruturava o processo de maturação de sua compreensão messiânico-cristológica acerca do herói. Nesse contexto, juntamente com a perspectiva cristológica ressignificada nas Tradições Básicas ${ }^{11}$ (TB), o discurso do herói-rei joanino torna-se querigma oralizado e imbrica-se com o processo de ressignificação messianológica joanina.

Em síntese, acreditamos que o processo de (re)configuração do davidismo popular $^{12}$ no círculo das tradições joaninas se estabeleceu fundamentalmente sob dois parâmetros:

1 - A compreensão ainda que em germe que a realeza de Jesus superava os paradigmas e estruturas ideológicas intrínsecas aos messianismos do seu tempo (inclusive as expectativas do davidismo popular).

2 - A instalação de um referencial messiânico crítico e subversivo que se estrutura sob a proposição paradigmática da não violência ${ }^{13}$.

Esse processo de ressignificação cristológica, a nosso ver, fixa-se como fator de uma eclosão efeitual ${ }^{14}$ que se desencadeia, sobretudo, no domínio das relações da

${ }^{10}$ Cf. GOPPELT, Leonhard. Teologia do Novo testamento. Trad. Martin Dreher e IIson Kayser. São Paulo: Teológica, 2003. KONINGS, Johan. "Meu reino não é deste mundo": de que se trata? Revista de Interpretação Bíblica Latino-Americana, Petrópolis; São Leopoldo, n. 17, p. 54-64, 1994. QUESNEL, Michel. Introdução. In: Evangelho e Reino de Deus. Trad. M. Cecília de M. Duprat. São Paulo: Paulus, 1997. p. 7-11. Diferente da alta concentração acerca da temática Reino de Deus no material sinótico, no QE a expressão "Reino de Deus" ocorre apenas duas vezes, sendo em João 3.3 e 3.5, seguido pela expressão "meu reino", observada três vezes em João 18.36-37 (GOPPELT, 2003). Podemos dizer que "João pouco fala em 'reino', mas os casos em que o termo aparece são muito significativos. Quem fala do reino em João é só Jesus [...] A razão é simples: só Jesus pode falar do seu reino sem mal-entendido" (KONINGS, 1994, p. 56). No QE Jesus é quem tem a voz, ele é o agente querigmático do seu Reino, visto que "as comunidades nas quais as tradições evangélicas foram elaboradas não teriam razão alguma de atribuir a Jesus palavras sobre o Reino de Deus, se ele mesmo não as tivesse realmente pronunciado" (QUESNEL, 1997, p. 11).

${ }_{11}$ Acerca das Tradições Básicas joaninas, cf. VIDAL, 2013.

12 As memórias e fontes incipientes acerca do herói joanino apontam para um parâmetro de dialogicidade entre o davidismo popular vigente no período do segundo templo e o messianismo real adotado pela comunidade joanina desde suas Tradições Básicas. Essa aproximação se estabelece a partir dos seguintes fatores dialógicos: 1) a contemporaneidade histórica em relação ao quadro de revoltas populares e geografia jerosolimitana dos grupos joaninos; 2) o fato de a comunidade joanina compreender Jesus como um Messias subversivo às estruturas do judaísmo e às práticas de dominação do Império Romano; 3) o locus estratigráfico, assim como a dinamicidade campesina atribuída tanto a Jesus quanto aos seus primeiros seguidores; 4) a proximidade do Jesus da tradição joanina em relação aos marginalizados, pobres e doentes; 5) o senso de partilha e de justiça do Jesus joanino e da comunidade; 6) o perfil marginal e subversivo dos primeiros seguidores de Jesus. Entretanto, no contexto da saga cristológica do herói joanino, concebemos que existe algo para além de uma plataforma associativa, na medida em que as Tradições Básicas não só aproximam o Jesus joanino do perfil davídico popular, mas, sobretudo, (re)leem e (re)configuram o referencial prototípico davídico a partir de sua própria compreensão acerca do herói do Quarto Evangelho (GUERRA, 2018, p. 57-62). Cf. também em GUERRA, Danilo Dourado. Messias e heróis: a ressignificação do messianismo popular na comunidade joanina. Fragmentos de cultura, Goiânia, n. 3, v. 25, p. 325-340, jul./set. 2015 b.

13 GUERRA, 2018, p. 63-73.

${ }^{14}$ Cf. GADAMER, 1997. 
comunidade, e, por consequência, em seu posicionamento heterotópico em relação ao cosmos em que habita.

Não obstante toda a polissemia em relação ao "mundo" que perpassa todo o corpus joanino, importa-nos aqui explicitar a representação do mundo em João 18.36 como um ordenamento sistêmico axiológico maligno de poderes e dominação ${ }^{15}$, que se manifesta a partir de paradigmas latreocráticos/teatrocráticos ${ }^{16}$ divinizantes e cultuais. ${ }^{17}$ Sob essa ordem injusta, o "mundo-humanidade aliena-se de Deus ao rejeitar seu projeto criador aceitando a ideologia que o oculta, os falsos valores próprios de sistema de violência e morte, personificado no "chefe do mundo/desta ordem" "18. Em síntese, o cosmos joanino em João 18.36 “é concretizado em dois círculos concêntricos: um mais amplo, a sociedade do Império Romano, e um mais restrito, representado pelo termo 'os judeus" "19. Nesse panorama, "apesar do conflito entre o judaísmo e o poder romano, o Quarto Evangelho situa ambos do lado 'deste mundo' e acentua a solidariedade entre os dois" ${ }^{20}$. Esse é o cenário em que a realeza de Jesus prefigura um modelo conflituoso da comunidade joanina tanto em relação ao Império Romano, quanto em relação ao judaísmo rabínico em (re)formulação. ${ }^{21}$ Nessa paisagem de ressignificações e efeitos, a estruturação de uma cristologia desviante assinala o status de uma comunidade desviante. ${ }^{22}$

Imersos em uma arena crítica, ao compreenderem os significados do herói-rei e de sua basileia, os grupos joaninos figuram, por sua vez, como heterotopias ${ }^{23} \mathrm{de}$

${ }^{15}$ Cf. RICHARD, Pablo. Chaves para uma re-leitura histórica e libertadora: Quarto Evangelho e Cartas. Revista de Interpretação Bíblica Latino-Americana, Petrópolis, v. 1, n. 17, p. 7-26, 1994. MATEOS, Juan; BARRETO, Juan. Vocabulário teológico do Evangelho de São João. Trad. Alberto Costa. São Paulo: Paulinas, 1989. p. 202.

16 Acerca das categorias analíticas latreocracia: "poder cultual" e teatrocracia: "poder teatral", ver em GUERRA, 2018, p. 138-234.

17 GUERRA, 2018, p. 359.

18 MATEOS; BARRETO, 1989, p. 202.

${ }_{19}$ KONINGS, Johan. Evangelho segundo João: amor e fidelidade. São Paulo: Loyola, 2000. p. 46-47.

${ }^{20}$ KONINGS, 1994, p. 57.

${ }^{21}$ Longe de se restringir apenas ao círculo judaico e distante de ser uma tentativa de instituição de qualquer tipo de antissemitismo, a concepção cosmológica joanina aborda de forma crítica as estruturas de poder vigentes de uma forma global. Nas palavras de Richard (1994, p. 13): "O mundo inimigo de Jesus e da comunidade do discípulo amado é uma realidade universal; às vezes é identificado com 'os judeus', mas é muito mais amplo do que este grupo específico. É o mundo sócio-religioso [sic] inimigo de Deus, de Jesus, da luz, da vida, do Espírito, dos discípulos. Tem uma dimensão espiritual e diabólica, mas também é uma realidade material, social e política”. "A denotação universal do termo 'o mundo' ultrapassa o sistema judaico, que se apresenta como paradigma dos sistemas de injustiça. $\mathrm{O}$ que caracteriza no evangelho os componentes do 'mundo' não é ser judeus de raça, mas ser inimigos do homem por constituir um sistema opressor baseado no poder do dinheiro" (MATEOS; BARRETO, 1989, p. 203). Cf. GUERRA, 2015a, p. 15.

22 Cf. STEGEMANN; STEGEMANN, 2004, p. 275.

${ }^{23}$ Acerca do conceito de heterotopia, cf. FOUCAULT, Michel. Outros espaços. In: MOTTA, Manoel Barros da (Org.). Estética: literatura e pintura, música e cinema. Trad. Inês Autran Dourado Barbosa. Rio de Janeiro: Forense Universitária, 2009. p. 411-422. Em síntese, segundo o autor, as heterotopias são: lugares reais, lugares efetivos, lugares que são delineados na própria instituição da sociedade, e que são espécies de contraposicionamentos, espécies de utopias efetivamente realizadas nas quais os posicionamentos reais que podem se encontrar no interior da cultura estão ao mesmo tempo representados, contestados 
desvio no tocante às estruturas paradigmáticas de dominação ao seu entorno. Nesse aspecto, esses atuam como vozes/espaços de resistência ${ }^{24}$, que não só renunciam, mas, essencialmente, desafiam e transformaram a fisionomia dos espaços politicamente ordenados e relações de poder a sua volta. Nessa esfera onde se anuncia o rei, a basileia se manifesta. ${ }^{25}$

No panorama da saga cristológica ${ }^{26}$ da comunidade do Quarto Evangelho, uma plataforma efeitual desencadeada pelo processo de ressignificação cristológica encontra-se, por sua vez, diante do microcosmo joanino. Nesse palco circunstancial, as implicações dessa dynamis ressignificante instauram-se visíveis no querigma cristológico de uma comunidade que, vista sob uma arena de horizontes bipartidos e efeitualidades, assim como o herói, também desafiou as estruturas judaicas do seu tempo.

Situamos nossa busca nos inícios de 70 d.C., período da saga cristológica do herói em que a comunidade joanina ainda frequentava o espaço sinagogal. Nesse momento, diferente do espaço de debates e homilias intrasinagogais de outrora ${ }^{27}$, a sinagoga transforma-se em uma arena de batalhas midráxicas ${ }^{28}$ e messianológicas, na qual o querigma cristológico joanino se fixava como uma ameaça ao ideário messiânico rabínico. Nessa conjuntura, a localização da comunidade no norte da Palestina explicaria a tensão dos grupos joaninos com o judaísmo oficial, muito influente no reino do judeu Agripa II. ${ }^{29}$

Algo relevante a ser considerado é que as referências ao título de Messias passaram a acontecer de forma acentuada após a destruição de Jerusalém (70 d.C.), justamente na época de reformulação do judaísmo. "Essa afirmação nos leva a acreditar que o embate sinagogal entre o judaísmo rabínico (pós-70) e a comunidade joanina aconteceu no momento em que o título Messias se coloca em evidência e em debate" ${ }^{\text {"31. }}$.

Sob essa perspectiva, na medida em que o conflito entre o judaísmo rabíni$\mathrm{co}^{32}$ e a comunidade joanina estruturava-se fundamentalmente na esfera dos debates messianológicos, o presente artigo tem por finalidade visibilizar os bastidores desse conflito e, por consequência, da expulsão sinagogal. Nesse intento, iremos propor basicamente que, no âmbito da saga cristológica do herói, a dinâmica de ressignifica-

e invertidos, espécies de lugares que estão fora de todos os lugares, embora eles sejam efetivamente localizáveis (FOUCAULT, 2009, p. 415).

${ }^{24}$ Maiores informações em GUERRA, 2015a, 2018 e RICHTER REIMER, Ivoni. Construção de heterotopias socioculturais nas obras de comunidades judaico-cristãs. Caminhos, Goiânia, v. 3, n. 1, p. 113-122, jan.jjun. 2004.

${ }^{25}$ MEINCKE, Silvio. Luta pela terra e Reino de Deus. São Leopoldo: Sinodal, 1988. p. 48.

${ }^{26}$ A saga cristológica do herói joanino se constitui em um enredo metodológico-reconstitutivo proposto para a identificação do processo de compreensão cristológica da comunidade do Quarto Evangelho (GUERRA, 2018).

${ }^{27}$ BROWN, Raymond E. A comunidade do discípulo amado. Trad. Euclides Carneiro da Silva. São Paulo: Paulinas, 1983.

${ }^{28}$ MARTYN, 1979a, p. 118; LINDARS, 2000, p. 71-72.

${ }^{29}$ VIDAL, 2013, p. 91; WENGST, 1988.

${ }_{30}$ ABRAHAMS apud DODD, Charles Harold. A interpretação do Quarto Evangelho. Trad. José Raimundo Vidigal. São Paulo: Teológica, 2003. p. 124.

${ }^{31}$ GUERRA, 2015a, p. 59.

32 Em relação ao judaísmo rabínico pós-70 d.C., ver DREW, Robert. Course book: Judaism, Christianity and Islam, to the beginnings of modern civilization. Nashville: Vanderbilt University, 2016. 
ção do davidismo popular e, por conseguinte, de configuração da cristologia joanina, testemunhada, sobretudo no fragmento João 18.36 como memória querigmatizada, não somente relaciona-se com os motivos do conflito entre a comunidade joanina e o rabinismo em formulação, quanto fundamentalmente, instaura-se, de forma efeitual, como um elemento catalisador da expulsão dos grupos joaninos da sinagoga. Para tanto, primeiramente, far-se-á referência ao contexto histórico e problematizações relacionados ao conflito e à expulsão sinagogal. Na sequência, versar-se-á propriamente acerca do elo efeitual entre o querigma cristológico joanino e a expulsão da comunidade joanina do judaísmo.

\section{Conflitos e problematizações: considerações preambulares}

Antes de qualquer análise, devemo-nos retomar o complexo cenário histórico em que se configurou o drama ${ }^{33}$ da expulsão joanina. Referimo-nos, fundamentalmente, ao processo de reformulação do cenário religioso judaico ocorrido pós-70.d.C. ${ }^{34}$ Nessa paisagem de efeitualidades ${ }^{35}$ foi estabelecido por parte dos fariseus/rabinos um programa de homogeneização/unificação doutrinário-teológica de caráter não sectário ${ }^{36}$, que tinha como fluxograma basilar uma nova autodefinição do judaísmo ${ }^{37}$, sobretudo a partir de uma definição da ortodoxia e de um projeto de conservação da tradição. ${ }^{38}$

33 Essa expressão é utilizada por MARTYN, 1979a.

${ }^{34} \mathrm{O}$ marco histórico que tem delimitado as pesquisas em relação ao Quarto Evangelho encontra-se na destruição de Jerusalém e do seu Templo nos anos 70 d.C., o que provocou uma reformulação na cena religiosa judaica. No que se refere a esse assunto, cf. ASIEDU-PEPRAH, Martin. Johannine Sabbath Conflicts as Juridical Controversy. Tübingen: Mohr Siebeck, 2001. BOISMARD, Marie-Émile. All'alba del cristianesimo: prima della nascita dei dogmi. Casale Monferrato: Piemme, 2000. COHEN, Shaye J. D. From the Maccabees to the Mishnah. Louisville; London: Westminster John Knox, 2006. _. The Significance of Yavneh and Other Essays in Jewish Hellenism. Tübingen: Mohr Siebeck, 2010. (Texts \& Studies in Ancient Judaism). p. 216ss. SCHIFFMAN, Lawrence H. Early Judaism and rabbinic Judaism. In: COLliNS, John J.; HARLOW, Daniel C. (Orgs.). Early Judaism: A Comprehensive Overview. Cambridge: Eerdmans, 2012. p. 420-434. ALEXANDER, Philip S. The king messiah in rabbinic Judaism. In: DAY, John (Org.). King and Messiah in Israel and the Ancient Near East: Proceedings of the Oxford Old Testament Seminar. London; New York: T\&T Clark International, 2013. p. 456-473. KONINGS, 2000. STEGEMANN; STEGEMANN, 2004, p. 254-282; VIDAL, 2013; DREW, 2016.

35 Os efeitos da destruição do templo em 70 d.C. sobre os judeus foram numerosos e variados. Entre esses estavam as dificuldades teológicas causadas pela cessação do culto sacrificial; a perda do centro sagrado do cosmos; a destruição dos símbolos físicos da presença de Deus; o confisco de terras e propriedades; as dificuldades sociais causadas pelo massacre ou escravização de um número enorme de pessoas e a perda das instituições centrais do Estado. Essas dificuldades foram sem dúvida suficientemente rigorosas e numerosas para constituírem uma "crise" ou "catástrofe" para os judeus daquele tempo (COHEN, 2010, p. 27-28).

${ }^{36}$ COHEN, 2006; SCHIFFMAN, 2012, p. 420-434.

37 WENGST, 1988; ASIEDU-PEPRAH, 2001.

38 COHEN, 2006, p. 28; 222-223. Na concepção de Cohen, os rabinos haviam aceitado muitas das inovações teológicas, legais e institucionais do período do Segundo Templo. Todavia, no período pós-70, assim como seus antepassados e seus descendentes, os rabinos viram-se não como os criadores de algo novo, mas como os portadores de algo velho, que, por sua vez, deveria ser conservado. 
Dentro dessa reorganização, os fariseus escreveram um corpo doutrinário visando conservar a identidade do povo judeu, elaboraram 18 bênçãos voltadas aos judeus e ao mesmo tempo escreveram uma maldição destinada aos "nozrim" ou cristãos. Nesse processo também fixaram o calendário das festas judaicas, fixaram o cânon do Antigo Testamento, definiram a liturgia sinagogal. A partir de então a sinagoga se tornara um sinônimo do judaísmo rabínico. ${ }^{39}$

Tal agenda (re)configurante estruturava-se essencialmente sob um senso de zelo teológico ${ }^{40}$ e um ideário de autopreservação religioso-comunitário diametralmente vinculado a um parâmetro de integração e consenso da maioria. ${ }^{41}$

Esse quadro histórico-estrutural engendra-se em um delicado momento político, social e religioso, em que os fundamentos do judaísmo mais do que nunca se quantizavam à custa da condescendência ${ }^{42}$ das autoridades romanas. ${ }^{43}$ Nessa cena, a preservação da religião judaica era mais importante que a independência política dos judeus, e por isso qualquer postura desviante ${ }^{44}$ ou discurso religioso divergente aos parâmetros da ortodoxia rabínica não poderia ser suportado e acarretava a expulsão ${ }^{45}$ daqueles que eram tidos como hereges e concorrentes. ${ }^{46}$

Tendo em vista essa conjuntura, os conflitos intrajudaicos pós-70 culminaram basicamente em duas experiências negativas:

Primeira, a exclusão religiosa ou social dos grupos messiânicos da população judaica majoritária. Ela culminou, resultou, por fim, na $12^{\mathrm{a}}$ bênção da Oração das Dezoito Preces. Segunda, os propagandistas crentes em Cristo foram castigados nas sinagogas e eventualmente expulsos. Para as duas experiências se deve pressupor que os judeus

${ }^{39}$ FERREIRA, Joel Antônio. Jesus na origem do cristianismo: os vários grupos que iniciaram o cristianismo. Goiânia: PUC Goiás, 2012. p. 127.

${ }^{40}$ No panorama rabínico, esse senso de "zelo teológico" judaico relacionava-se com o voltar à Lei para se autoproteger da ira divina (WENGST apud TEPEDINO, 1993).

${ }^{41}$ WENGST, 1988; STEGEMANN; STEGEMANN, 2004, p. 275.

${ }^{42}$ De acordo com DREW (2016), nesse período a atitude dos romanos para com os rabinos geralmente era benigna, visto que aparentemente o judaísmo não representava nenhum perigo para o Império.

${ }^{43}$ VIDAL, 2013, p. 252; DREW, 2016, [s.p.].

${ }^{44}$ De acordo com STEGEMANN; STEGEMANN (2004, p. 279), "o comportamento do desviante é definido em cada caso pela sociedade majoritária". Essa sociedade impõe limites e regras para a preservação de sua própria identidade. Foi o que aconteceu com o judaísmo pós-70. Sob essa ótica, aqueles que rompiam ou descaracterizavam a identidade judaica eram tidos como desviantes. Segundo Becker (apud STEGEMANN; STEGEMANN, 2004, p. 279), a desviância é um fruto social. Para Erikson (apud STEGEMANN; STEGEMANN 2004, p. 279), "a imposição de normas da sociedade majoritária contra desviantes é favorecida particularmente por crises sociais".

${ }^{45}$ Assim como COHEN (2006, p. 21), compreendemos a expulsão da sinagoga como um processo e não como um evento. Naquele tempo, essa separação manifestava-se de maneiras diferentes em cada comunidade onde judeus e cristãos habitavam juntos. Nesse contexto, parte essencial desse processo ocorreu devido às comunidades cristãs estarem se tornando gradativamente mais gentílicas e menos judaicas.

${ }^{46}$ STEGEMANN; STEGEMANN, 2004, p. 275; VIDAL, 2013, p. 90. Dentro dessa realidade, "a população majoritária exclui os judeus crentes em Cristo por meio de injúrias verbais supostamente referentes às suas convicções religiosas divergentes" (STEGEMANN; STEGEMANN, 2004, p. 275). No tocante ao termo "concorrentes", cf. COHEN, 2006. 
crentes em Cristo são percebidos pela população majoritária como um grupo religioso desviante dentro do judaísmo ${ }^{47}$.

Esse pano de fundo, entretecido por conflitos, reptos e contingências, esteia-se, por sua vez, como contexto histórico vivenciado pelos grupos joaninos. À luz desse panorama, delineia-se na arena sinagogal uma batalha cristológica ${ }^{48}$ na qual "a confissão de Jesus como Senhor messiânico se converteu na razão fundamental da expulsão dos grupos joaninos do seio da sinagoga"49, e, por conseguinte, do judaísmo. ${ }^{50}$

Aqui, chegamos a um ponto de nossa problematização.

Tendo em vista a gama de dados elencados até o momento, como grande parte dos exegetas do Quarto Evangelho, concordamos com a existência de um fator querigmático e cristológico relacionado à exclusão dos grupos joaninos do ambiente sinagogal pós-70 d.C. Nesse aspecto, como já postulamos, apesar da variabilidade de hipóteses $^{51}$ que orbitam a temática, corroboramos a afirmativa de que a comunidade joanina passou a ser expulsa ${ }^{52}$ da sinagoga substancialmente por proclamar Jesus como o Messias. ${ }^{53}$

Por outra parte, munidos desse pressuposto, almejamos mais um passo. Nesse deslocamento, como já assinalado, objetivamos não somente manter a assertiva de que os grupos joaninos foram expulsos da sinagoga por proclamarem Jesus como o Messias, mas de forma substancial, ousamos propor o perfil desse Messias. À luz dessa intenção, a evidenciação do Jesus joanino como um Messias do tipo davídico

47 STEGEMANN; STEGEMANN, 2004, p. 275. No ponto de vista de COHEN, 2006, p. 21, a bênção contra os hereges (Birkat há-Minim) possui um viés de legitimidade e pode ser concebida como um marco importante na autodefinição de judaísmo rabínico. Através dela os rabinos oravam para que Deus destruísse todos aqueles que persistissem em manter uma identidade separatista em um mundo sem templo. Maiores informações acerca da Birkat há-Minim, cf. STEGEMANN; STEGEMANN, 2004, p. 268-272 e VIDAL, 2013, p. 47.

48 BROWN, 1983; TEPEDINO, 1993; ASIEDU-PEPRAH, 2001.

49 VIDAL, 2013, p. 90. (tradução própria).

50 Segundo TEPEDINO (1993, p. 195), antes de 70 d.C., o solo comum (judaísmo) tornava compatível o convívio entre elementos heterogêneos. No entanto, diante de um processo de reformulação e homogeneização do judaísmo, a confissão do Messias feito pela comunidade joanina rompe com esse solo comum. Nesse contexto, as autoridades antes aceitas perdem sua legitimidade junto aos membros que se afastam ou são afastados. No caso da comunidade, são expulsos da sinagoga e deparam-se com um novo tipo de estruturação social que anuncia uma comunidade agora separada religiosa e socialmente. Cf. KONINGS, 2000; STEGEMANN; STEGEMANN, 2004; ALMEIDA, 2009 e VIDAL, 2013.

${ }^{51}$ Cf. BROWN, 1983; LINDARS, 2000; VIDAL, 2013. Acerca da hipótese do Messias - profeta- mosaico, ver em MARTYN, 1979a, p. 114-118 e BOISMARD, 2000, p. 104-106.

52 Maiores informações em BLANCHARD, Yves-Marie. São João. Trad. Mariana N. Ribeiro Echalar. São Paulo: Paulinas, 2004. Segundo BLANCHARD, 2004, p. 33, “o Evangelho de João é o único texto do Novo Testamento a usar um termo técnico, o adjetivo aposynagôgos, para designar o banimento do mundo judaico, não por livre e espontânea vontade das comunidades joaninas, mas sim por uma ação violenta determinada pelas autoridades judaicas". Na concepção de STEGEMANN; STEGEMANN, 2004, a chave para a compreensão do teor dessa expulsão está no ineditismo da expressão aposynagogos. Segundo os autores, a criação de uma nova expressão pressupõe uma nova experiência. Essa experiência trata, antes de tudo, unicamente da exclusão dos crentes em Cristo do culto sinagogal. Conforme TEPEDINO, 1993, nesse contexto, primeiro eram expulsos indivíduos, depois o grupo.

53 VIDAL, 2013, p. 90. 
popular ressignificado conduz-nos a alguns questionamentos acerca dos bastidores da expulsão, a saber:

Em um panorama de homogeneização doutrinário-teológica, a pluralidade de messianismos e, sobretudo de davidismos, pode ser assinalada como um fator de conflito entre o judaísmo rabínico e os grupos joaninos? Dentro desse contexto, haveria uma interface conflituosa entre o ideário do Messias popular joanino e o ideário messiânico rabínico pós-70? E, nesse sentido, como a dinâmica de ressignificação do davidismo popular e, por conseguinte, de configuração da cristologia joanina, implícita na anamnese e querigma da comunidade, relaciona-se com o processo de expulsão da sinagoga?

Diante dessas indagações, a priori, o que podemos aferir é que a especificidade do perfil messiânico do herói joanino abre-nos pressupostos investigativos no que se refere à gama de conflitos e efeitos arquitetados nos bastidores da expulsão sinagogal. Nesse palco exploratório, o processo de ressignificação messiânico-cristológica implícito no fragmento de João 18.36, visto antes de tudo como memória e querigma joanino, faz-se protagonista ${ }^{54}$ de uma hipótese a ser considerada. Acerca disso trataremos a seguir.

\section{Os bastidores da expulsão}

Chegamos ao mote de nossa investigação, no qual, a partir da hipótese primeva do fragmento de João 18.36 como memória, pretendemos adentrar nos bastidores do drama da expulsão dos grupos joaninos da sinagoga.

Tendo em consideração o viés histórico-contextual apresentado, suspeitamos que o conteúdo dos debates messianológicos entre a comunidade joanina e os judeus rabinos tenha como elemento significativo um conflito entre ideários e perfis messiânicos.

Alegamos tal proposição ao passo que apreendemos que, no período pós-70 d.C., as expectativas messiânicas em relação a um rei davídico continuavam vivas nos corações judaicos ${ }^{55}$, inclusive no ideário rabínico. ${ }^{56}$ Nessa paisagem, em meio à ótica bipartida de davidismos, adotamos a tese de que o rabinismo sinagogal articulava-se dentro de uma expectativa messiânica de perfil real oficial.

No âmbito de nossa investigação, o coeficiente análogo entre o messianismo oficial e o judaísmo rabínico faz-se significativo ao passo que possibilita a visualização de um background dos conflitos no panorama joanino. Sob essa perspectiva, nosso parâmetro de aproximação entre o judaísmo rabínico pós-70 d.C., e o messianismo davídico do tipo oficial estrutura-se a partir de dois critérios dialógicos: 1) a

\footnotetext{
${ }^{54}$ No panorama da exegese joanina, a expulsão sinagogal pode ser explicada a partir de vários textos e perspectivas acerca das configurações da cristologia joanina. Nesse contexto, cf. MARTYN, 1979a, p. 114-118; LINDARS, 2000, p. 71s e VIDAL, 2013. Entretanto, nesta investigação recorreremos basicamente ao fragmento-chave de João 18.36 para efetuar essa explicação.

55 ASIEDU-PEPRAH, 2001, p. 220.

56 Naquele tempo, o Messias Ben David fazia-se figura predominante no judaísmo messiânico rabínico (SCHÄFER, 2012, p. 236). Ver também WILL, 1989, p. 37; POMYKALA, 2004, p. 34 e SCHIFFMAN, 2012.
} 
identificação de um messianismo real davídico como matriz messiânica do judaísmo rabínico $^{57} ; 2$ ) a correlação entre o messianismo real rabínico e o texto de 2 Samuel 7.

No que se refere ao primeiro critério, compreendemos que, desde o período do segundo templo, os fariseus, que mais tarde se tornariam rabinos, defendiam um messianismo real davídico. ${ }^{58}$ Sob esse prisma, podemos assinalar que o messianismo, quando ocorre na literatura rabínica clássica, tem em vista o estabelecimento de um Estado judeu régio, no tempo histórico real. ${ }^{59}$ Nessa conjuntura, "os Salmos de Salomão que procedem do judaísmo rabínico e sinagogal concentram sua expectativa no ungido do Senhor $(17,36 ; 18,6.8)$, no filho de Davi $(17,23)$, o rei salvador do tempo final que procede da linhagem davídica"60.

No tocante ao segundo critério, a leitura de Ferreira (2015) contribui com a associação do perfil messiânico rabínico ao texto de 2 Samuel 7.12-16. Na concepção do autor, essa analogia encontra-se desde o período do segundo templo, época em que a maioria dos partidos judaicos era adepta do protótipo messiânico davídico oficial advindo dessa tradição textual. ${ }^{61}$ Em suas palavras:

Normalmente, por falta de material suficiente, no nível da pesquisa, a questão do Messias é analisada, a partir dos grupos que registraram, por escrito, suas visões e interpretações. Esses estavam ligados a instituições fortes ou envolvidos com o poder: saduceus e sacerdotes, escribas, herodianos, fariseus e suas diversas tendências, essênios etc. A partir desses, muito se escreveu e se interpretou. É evidente que a leitura de Natã a David, feita por esses grupos, espelhará os seus universos ideológicos. O referido texto da profecia de Natã $(2 S m 7,12-16)$ passou a ser uma esperança "oficial", isto é, daqueles que estavam ligados ao poder. A história oficial de Israel, quase sempre, privilegiou os relatos contados pela minoria, em geral, aqueles que detinham o poder e manipulavam as consciências dos pobres ${ }^{62}$.

${ }^{57}$ Cf. WILL, 1989, p. 37; KESSLER, 2003, p. 51; POMYKALA, 2004, p. 34; SCHIFFMAN, 2012; VIDAL, 2013, p. 222; ALEXANDER, 2013, p. 472 e SCHILLEBEECKX, 2014, p. 416-417.

${ }^{58}$ POMYKALA, Kenneth E. Images of David in early Judaism. In: EVANS, Craig A (Org.). Of Scribes and Sages: Early Jewish Interpretation and Transmission of Scripture: Ancient Versions and Traditions. London; New York: T\&T Clark International, 2004. p. 33-46. SCHILLEBEECKX, Edward. Jesus: An Experiment in Christology. London; New York: Bloomsbury T\&T Clark, 2014. p. 416. WILL, James E. A Christology of Peace. Louisville: Westminster John Knox, 1989. p. 37.

${ }^{59}$ ALEXANDER, 2013, p. 472.

${ }^{60}$ KESSLER, Hans. Manual de cristología. Trad. Claudio Gancho y Marciano Villanueva. Barcelona: Herder, 2003. p. 51. (Tradução própria).

${ }^{61}$ Acerca da temática, Cf. HORSLEY, Richard A.; HANSON, John S. Bandidos, profetas e Messias: movimentos populares no tempo de Jesus. Trad. Edwino Aloysius Royer. São Paulo: Paulus, 1995. p. 91-92. SCHWANTES, Milton. Uma promessa de Dinastia para Davi na Ótica de Jerusalém: anotações sobre Messianismo e Davidismo em 2 Samuel 7. Revista de Cultura Teológica, São Paulo, v. 16, n. 63, p. 9-32, abr./jun. 2008.

${ }^{62}$ FERREIRA, Joel Antônio. O Messias/rei Jesus e os Messias camponeses de seu tempo. Caminhos, Goiânia, n. 2, v. 13, p. 336-352, jul./dez. 2015. p. 337-338. (Grifos nossos). 
Diante desse jogo de poderes, avaliamos que em um contexto de polêmica joanina com a sinagoga, a concepção judaica oficial acerca do Messias descendente de Davi era baseada em 2 Samuel 7.12-16. ${ }^{63}$ Aqui se estabelece nossa aproximação.

Sob esse quadro histórico, configuram-se os bastidores de conflitos e efeitualidades almejados nesta investigação. Haja vista esses argumentos, assinalamos fundamentalmente que, no background joanino, travou-se um embate messianológico permeado de forma substancial por conflitos entre perfis messiânicos e interesses. Esse embate encadeava-se entre o ideário messiânico davídico oficial adotado pelos rabinos pós-70 d.C. e o ideário messiânico davídico popular ressignificado estruturado no âmbito da saga cristológica da comunidade. ${ }^{64}$

A nosso ver, o referido embate messianológico instaurou-se essencialmente a partir do querigma do herói-rei e de seu reino no espaço sinagogal. Nesse espaço, a anamnese e a proclamação de Jesus como o Messias popular ressignificado se estabeleceram como matriz conflituosa, sobretudo na medida em que o Messias joanino e sua basileia não coadunavam com o ideário real rabínico. ${ }^{65}$

Nesse tablado de incompatibilidades, enquanto os rabinos ansiavam por um Messias político que restaurasse as glórias da era davídica e reconstruísse o templo judaico ${ }^{66}$, a comunidade joanina, a partir de um processo de ressignificação cristológico, anunciava um Messias sem trono e sem templo, e uma basileia estruturada sob pressupostos de uma alta política. ${ }^{67}$ Dessa forma, enquanto o messianismo rabínico possuía status de um processo político deste mundo ${ }^{68}$, o messianismo joanino proclamava um Messias-rei e os paradigmas politizantes de matiz superior inerente a um reino que não se origina neste cosmos, mas que atua nele. Um sistema de poder celeste, com matiz sobrenatural, que propõe a configuração de uma política que se manifesta na terra. ${ }^{69} \mathrm{O}$ sentido desse reino pode ser observado na expressão "ser de" (einai ek), que figura em João 18.36. Essa "indica a procedência ou origem do 'reino' de Jesus, e não o lugar onde se realiza esse 'reino': o 'reino' de Jesus não tem sua origem ('não é de') 'este mundo' ou 'aqui', porém exerce seu senhorio no âmbito deste mundo" "70.

Essa realidade (re)significante da basileia do Cristo joanino possui antes de tudo caráter fenomenológico/soteriológico ${ }^{71}$ e é regida por uma gama de princípios cristotópicos que envolvem o amor, justiça, igualdade, partilha, liberdade entre ou-

${ }^{63}$ VIDAL, 2013, p. 222.

${ }^{64}$ GUERRA, 2018.

${ }^{65}$ Na concepção de TEPEDINO, 1993, p. 201, o Jesus joanino não fora visto como o Messias por parte dos rabinos essencialmente pelo fato de que: a) sofrera morte vergonhosa na cruz; b) era proveniente da Galileia, quando se esperava que o Messias viesse de Belém, cidade de Davi; c) não era descendente de Davi.

${ }^{66}$ ASIEDU-PEPRAH, 2001; SCHIFFMAN, 2012, [s.p.].

${ }^{67}$ GUERRA, 2018.

${ }_{68}$ ALEXANDER, 2013, p. 472.

${ }^{69}$ Sob essa conjuntura, a basileia joanina configura-se em outro nível (GUERRA, 2015a) e evoca, nesse aspecto, uma dimensão transpolítica da existência (SHERMAN apud MOILA, Philip. Reinado de Deus e compromisso político. Estudos Teológicos, São Leopoldo, v. 30, p. 83-97, 1990. p. 92).

70 VIDAL, 2013, p. 415. (Tradução própria).

${ }^{71}$ SCHLOSSER, Jacques. O reinado de Deus na teologia bíblica. In: LACOSTE, Jean-Yves (Org.). Dicionário crítico de teologia. Trad. Paulo Meneses. São Paulo: Paulinas; Loyola, 2004. p. 1.500-1.504. 
tros. Esses preceitos sob um caráter de universalidade versam acerca da dignidade e felicidade aos seres humanos, e não para uns quantos. ${ }^{72}$

Por outra parte, nesse panorama dos embates messianológicos, avaliamos que o querigma joanino, à luz do protagonismo imagético do Messias ressignificado, também se fixou como matriz conflituosa, à proporção que, sob um prisma heterotópico, carregava em si uma proposta de quebra paradigmática no tocante às estruturas de tradicionamento do judaísmo, sobretudo em relação ao ideário messiânico real oficial.

Nas palavras de Tepedino, no panorama sinagogal joanino, o conflito entre maioria (judeus rabinos) e minoria (comunidade joanina) estabelecia um quadro de crise e se constituía num momento crítico para as representações tradicionais. ${ }^{73}$ Nesse aspecto, podemos abalizar que, em uma conjuntura de uniformização doutrinária, na qual os rabinos objetivavam a manutenção da tradição, o querigma de um protótipo messiânico não convencional teria provocado uma crise de tradição dentro do messianismo real oficial judaico. ${ }^{74}$

Diante desse cenário de crises e conflitos, o perfil messiânico atribuído ao Jesus joanino rompia com os parâmetros messianológicos tradicionais da época. Nesse sentido, o discurso do herói-rei acerca de sua basileia, com todas as suas implicações, tornava-se escândalo e ameaça herética religiosa e social para o mundo rabínico. ${ }^{75}$ Esse escândalo messianológico-cristológico, por sua vez, fora a causa da expulsão dos grupos joaninos da sinagoga. Às luzes dessa ribalta paradoxal, concordamos com a provável ótica rabínica de que o Jesus joanino não era rei, tampouco havia reinado. Ao menos, não como o mundo idealizava.

Ao ponderarmos esses dados, avaliamos que em uma arena de debates midráxicos e messianológicos pautada por um ideário de uniformização doutrinário-teológica não sectária, a proclamação do herói joanino como um Messias popular ressignificado fora, substancialmente, uma ameaça divergente às estruturas de tradicionamento do judaísmo rabínico em reformulação, principalmente no que se refere à expectativa messiânica davídica oficial adotada pelo rabinismo daquele tempo. Sob essa perspectiva, a especificidade e o conteúdo messianológico-cristológico do querigma joanino intrínseco no fragmento de João 18.36 como memória estrutura-se como coeficiente desencadeante de conflitos e efeitualidades e, nesse aspecto, instaura-se como elemento catalisador da expulsão dos grupos joaninos do espaço sinagogal.

De outro lado, no âmago desse background saturado de desafios e efeitualidades, não poderíamos deixar de considerar ainda que o drama da expulsão do espaço sinagogal também produziu seus resultados. Sob esse prisma contingencial, possivelmente o mais expressivo desdobramento desse episódio de conflitos seja a confecção

72 PANNENBERG, Wolfhart. Teología y reino de Dios. Salamanca: Sígueme, 1974.

73 TEPEDINO, 1993, p. 195.

74 DAVIES, W. D. The historical Jesus in the Johannine Christ. In: SMITH, Dwight Moody; CULPEPPER, Alan; BLACK, Carl Clifton (Orgs.). Exploring the Gospel of John: In Honor of D. Moody Smith. Louisville: Westminster John Knox, 1996. p. 43-64.

75 VIDAL, 2013, p. 49. 
do primeiro evangelho joanino $\left(E 1^{76}\right)$, escrito ainda durante o processo de expulsão da comunidade da sinagoga. Esse documento, por sua vez, fora elaborado pela escola joanina, por volta dos anos 80 d.C., a partir de um processo de releitura das Tradições Básicas $^{77}$, bem como de cooptação e reinterpretação de memórias e narrativas acerca do herói. Nessa ocasião, à luz de um paradigma reinterpretativo, os poetas joaninos traduzem em nuances textuais um discurso cristológico inédito no âmbito das narrativas cristãs originárias. Surge assim o fragmento João 18.36 em forma de texto. $\mathrm{Na}$ trama dessas linhas, os autores do evangelho joanino objetivaram mostrar de que ordem era a realeza de Jesus. Mas em vez de ensinar abstratamente tais verdades, conseguiram concretizá-las numa cena imortal. ${ }^{78}$ Essa cena, por seu turno, se instaura como elemento de reafirmação e consolidação da cristologia real joanina. ${ }^{79}$

\section{Considerações finais}

Os debates acerca do drama da expulsão dos grupos joaninos da sinagoga encontram-se longe de um desfecho. Essa constatação, em grande parte se estabelece conforme as hipóteses em relação ao metaponto histórico-axiológico desse evento continuam sendo (re)formuladas. Uma das propostas de atualização e (des)dobramento do principal motivo que desencadeou o processo de exclusão joanino do judaísmo em (re)formulação foi delineada nesta investigação. No decorrer dela, procuramos dar um passo a mais e decodificar, ainda que por espelho, o retrato messiânico do Cristo joanino.

No decorrer deste estudo, verificou-se que o registro inédito e o conteúdo cristológico de João 18.36 revelam, em grande proporção, o conteúdo dos conflitos entre os grupos joaninos e o cosmos à sua volta. Sob essa perspectiva, de forma pontual demonstrou-se que esses metapontos interagem diametralmente com o background da expulsão sinagogal.

Nas sendas desses bastidores, deparamo-nos com uma arena midráxica de debates instaurados a partir de um conflito entre perfis messiânicos e interesses. Nesse tablado, evidenciou-se que o conteúdo da expulsão dos grupos joaninos da sinagoga envolveu, de forma fundamental, uma gama de incompatibilidades interpretativo-doutrinárias relacionadas ao conteúdo da cristologia real desenvolvido na saga cristológica joanina. Essas divergências instauraram-se, sobretudo, no que se refere ao querigma de Jesus como um Messias do tipo popular ressignificado e a repercussão de um ideário cristológico real com matizes de ressignificação e renovação em relação às matrizes de tradicionamento e ao paradigma messiânico oficial defendido pelo judaísmo rabínico. Diante desses resultados analíticos, podemos afirmar que o escândalo messianológico-cristológico repercutido essencialmente no querigma do Cristo ressignificado em João 18.36 fora a causa da expulsão dos grupos joaninos da sinagoga.

\footnotetext{
76 Cf. VIDAL, 2013.

77 VIDAL, 2013, p. 47-48.

78 JAUBERT, Annie. Leitura do evangelho segundo João. Trad. Pe. José Raimundo Vidigal. São Paulo: Paulinas, 1982. p. 18-19.

79 GUERRA, 2018, p. 40-130.
} 
Mediante a estruturação desta tese, a pesquisa lança contribuições na medida em que constata no núcleo cristológico real joanino a estruturação de uma digital messianológica popular querigmática axiologicamente inversa ao tradicional parâmetro messianológico real oficial judaico. Nesse aspecto, esta pesquisa torna-se significativa, sobretudo, ao passo em que, ao lançar luzes a um debate ainda aberto, propõe o mapeamento da digital messiânica joanina e a conseguinte configuração de um protótipo messiânico davídico popular ressignificado como um caminho elucidativo até então não considerado no tocante ao conteúdo e background da expulsão dos grupos joaninos da sinagoga.

\section{Referências}

ALEXANDER, Philip S. The king messiah in rabbinic Judaism. In: DAY, John (Org.). King and Messiah in Israel and the Ancient Near East: Proceedings of the Oxford Old Testament Seminar. London; New York: T\&T Clark International, 2013. p. 456-473.

ASIEDU-PEPRAH, Martin. Johannine Sabbath Conflicts as Juridical Controversy. Tübingen: Mohr Siebeck, 2001.

BERNIER, Jonathan. Aposynagogos and the Historical Jesus in John: Rethinking the Historicity of the Johannine Expulsion Passages. Leiden: Brill, 2014.

BLANCHARD, Yves-Marie. São João. Trad. Mariana N. Ribeiro Echalar. São Paulo: Paulinas, 2004. BOISMARD, Marie-Émile. All'alba del cristianesimo: prima della nascita dei dogmi. Casale Monferrato: Piemme, 2000.

BROWN, Raymond E. A comunidade do discípulo amado. Trad. Euclides Carneiro da Silva. São Paulo: Paulinas, 1983.

BRO LARSEN, Kasper. Narrative Docetism: Christology and storytelling in the Gospel of John. In: BAUCKHAM, Richard; MOSSER, Carl (Orgs.). The Gospel of John and Christian theology. Grand Rapids: Eerdmans, 2008. p. 346-355.

COHEN, Shaye J. D. From the Maccabees to the Mishnah. Louisville; London: Westminster John Knox, 2006.

The Significance of Yavneh and Other Essays in Jewish Hellenism. Tübingen: Mohr

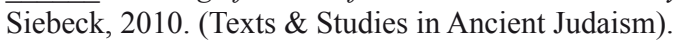

DAVIES, W. D. The historical Jesus in the Johannine Christ. In: SMITH, Dwight Moody; CULPEPPER, Alan; BLACK, Carl Clifton (Orgs.). Exploring the Gospel of John: In Honor of D. Moody Smith. Louisville: Westminster John Knox, 1996. p. 43-64.

DODD, Charles Harold. A interpretação do Quarto Evangelho. Trad. José Raimundo Vidigal. São Paulo: Teológica, 2003.

DREW, Robert. Course book: Judaism, Christianity and Islam, to the beginnings of modern civilization. Nashville: Vanderbilt University, 2016.

FERREIRA, Joel Antônio. Jesus na origem do cristianismo: os vários grupos que iniciaram o cristianismo. Goiânia: PUC Goiás, 2012.

. O Messias/rei Jesus e os Messias camponeses de seu tempo. Caminhos, Goiânia, n. 2, v. 13, p. 336-352, jul./dez. 2015.

FOUCAULT, Michel. Outros espaços. In: MOTTA, Manoel Barros da (Org.). Estética: literatura e pintura, música e cinema. Trad. Inês Autran Dourado Barbosa. Rio de Janeiro: Forense Universitária, 2009. p. 411-422.

GADAMER, Hans-Georg. Verdade e Método I: traços fundamentais de uma hermenêutica filosófica. Trad. Flávio Paulo Meuer. Petrópolis: Vozes, 1997. 
GOPPELT, Leonhard. Teologia do Novo testamento. Trad. Martin Dreher e IIson Kayser. São Paulo: Teológica, 2003.

GUERRA, Danilo Dourado. O Reino de Deus e o mundo dos homens: em busca da heterotopia joanina. Dissertação (Mestrado em Ciências da Religião) - Pontifícia Universidade Católica de Goiás, Goiânia, 2015a.

Messias e heróis: a ressignificação do messianismo popular na comunidade joanina.

Fragmentos de cultura, Goiânia, n. 3, v. 25, p. 325-340, jul./set. 2015 b.

Heróis em cena: a construção paradigmática contracultual da mesocristologia joanina. Tese

(Doutorado em Ciências da Religião) - Pontifícia Universidade Católica de Goiás, Goiânia, 2018.

HORSLEY, Richard A.; HANSON, John S. Bandidos, profetas e Messias: movimentos populares no tempo de Jesus. Trad. Edwino Aloysius Royer. São Paulo: Paulus, 1995.

JAUBERT, Annie. Leitura do evangelho segundo João. Trad. Pe. José Raimundo Vidigal. São Paulo: Paulinas, 1982.

KESSLER, Hans. Manual de cristología. Trad. Claudio Gancho y Marciano Villanueva. Barcelona: Herder, 2003.

KIERKEGAARD, Sören. Temor e Tremor. Trad. Torrieri Guimarães. Rio de Janeiro: Tecnoprint, [s.d.]. KONINGS, Johan. "Meu reino não é deste mundo": de que se trata? Revista de Interpretação Bíblica Latino-Americana, Petrópolis; São Leopoldo, n. 17, p. 54-64, 1994.

Evangelho segundo João: amor e fidelidade. São Paulo: Loyola, 2000.

LINDARS, B. John. In: The Johannine literature. Sheffield: Sheffield Academic Press, 2000. p. $30-109$.

MARTYN, J. Louis. History \& Theology in the Fourth Gospel. Nasville: Abingdon, 1979a.

. The gospel of John in Christian history: essays for interpreters. New York: Paulist, 1979b.

MATEOS, Juan; BARRETO, Juan. Vocabulário teológico do Evangelho de São João. Trad. Alberto Costa. São Paulo: Paulinas, 1989.

MEINCKE, Silvio. Luta pela terra e Reino de Deus. São Leopoldo: Sinodal, 1988.

MOILA, Philip. Reinado de Deus e compromisso político. Estudos Teológicos, São Leopoldo, v. 30, p. 83-97, 1990.

PANNENBERG, Wolfhart. Teología y reino de Dios. Salamanca: Sígueme, 1974.

POMYKALA, Kenneth E. Images of David in early Judaism. In: EVANS, Craig A (Org.). Of Scribes and Sages: Early Jewish Interpretation and Transmission of Scripture: Ancient Versions and Traditions. London; New York: T\&T Clark International, 2004. p. 33-46.

QUESNEL, Michel. Introdução. In: Evangelho e Reino de Deus. Trad. M. Cecília de M. Duprat. São Paulo: Paulus, 1997. p. 7-11.

RICHARD, Pablo. Chaves para uma re-leitura histórica e libertadora: Quarto Evangelho e Cartas. Revista de Interpretação Bíblica Latino-Americana, Petrópolis, v. 1, n. 17, p. 7-26, 1994.

RICHTER REIMER, Ivoni. Construção de heterotopias socioculturais nas obras de comunidades judaico-cristãs. Caminhos, Goiânia, v. 3, n. 1, p. 113- 122, jan./jun. 2004.

SCHÄFER, Peter. The Jewish Jesus: How Judaism and Christianity Shaped Each Other. New Jersey: Princeton University Press, 2012.

SCHIFFMAN, Lawrence H. Early Judaism and rabbinic Judaism. In: COLLINS, John J.; HARLOW, Daniel C. (Orgs.). Early Judaism: A Comprehensive Overview. Cambridge: Eerdmans, 2012. p. 420-434.

SCHILLEBEECKX, Edward. Jesus: An Experiment in Christology. London; New York: Bloomsbury T\&T Clark, 2014.

SCHLOSSER, Jacques. O reinado de Deus na teologia bíblica. In: LACOSTE, Jean-Yves (Org.). Dicionário crítico de teologia. Trad. Paulo Meneses. São Paulo: Paulinas; Loyola, 2004. p. 1.500-1.504. 
SCHWANTES, Milton. Uma promessa de Dinastia para Davi na Ótica de Jerusalém: anotações sobre Messianismo e Davidismo em 2Samuel 7. Revista de Cultura Teológica, São Paulo, v. 16, n. 63, p. 9-32, abr./jun. 2008.

STEGEMANN, Ekkehard W.; STEGEMANN, Wolfgang. História social do protocristianismo: os primórdios do judaísmo e as comunidades de Cristo no mundo mediterrâneo. Trad. Nélio Schneider. São Leopoldo: Sinodal, 2004.

TEPEDINO, Ana Maria Azevedo Lopes. Espiritualidade e ética: Jesus Cristo e a História da Comunidade joanina. Tese (Doutorado em Teologia) - PUC/RJ, Rio de Janeiro, 1993.

VIDAL, Senén. Evangelio y Cartas de Juan: Génesis de los textos juánicos. Bilbao: Mensajero, 2013. WENGST, Klaus. Interpretación del Evangelio de Juan. Salamanca: Sígueme, 1988.

WILL, James E. A Christology of Peace. Louisville: Westminster John Knox, 1989. 